\begin{tabular}{|c|c|c|c|}
\hline \multirow{3}{*}{$\begin{array}{r}\text { Case Reports in } \\
\text { Gastroenterology }\end{array}$} & \multirow{2}{*}{\multicolumn{2}{|c|}{ Case Rep Gastroenterol 2017;11:655-659 }} & \multirow[b]{3}{*}{$\begin{array}{l}\text { Karger } \\
\text { Open access }\end{array}$} \\
\hline & & & \\
\hline & $\begin{array}{l}\text { DOI: 10.1159/000479624 } \\
\text { Published online: November 2, } 2017\end{array}$ & $\begin{array}{l}\text { (c) } 2017 \text { The Author(s) } \\
\text { Published by S. Karger AG, Basel } \\
\text { www.karger.com/crg }\end{array}$ & \\
\hline & $\begin{array}{l}\text { This article is licensed under the } \\
\text { International License (CC BY-NC) } \\
\text { Usage and distribution for commercia }\end{array}$ & $\begin{array}{l}\text { nons Attribution-NonCommercial } 4.0 \\
\text { ger.com/Services/OpenAccessLicense). } \\
\text { uires written permission. }\end{array}$ & \\
\hline
\end{tabular}

\title{
Microvillus Inclusion Disease Variant in an Infant with Intractable Diarrhea
}

\author{
Badr M. Rasheed Alsaleem Amna Basheer M. Ahmed \\ Musa Ahmad Fageeh \\ Department of Pediatric Gastroenterology and Department of Pathology, Children's \\ Hospital, King Fahad Medical City, Riyadh, Saudi Arabia
}

\section{Keywords}

Microvillus inclusion disease $\cdot$ Intractable diarrhea $\cdot$ Whole exome sequencing $\cdot$ Syntaxin 3

\begin{abstract}
Microvillus inclusion disease (MVID) is a rare autosomal recessive congenital enteropathy characterized by intractable secretory diarrhea. We report a case of MVID variant with a homozygous gene mutation in syntaxin 3 (STX3). The patient is a male Saudi infant who presented shortly after birth with severe vomiting, metabolic acidosis, and mild diarrhea. Electron microscopy study for small intestinal biopsy was consistent with MVID. MYO5B gene mutation was excluded; subsequently, whole exome sequencing (WES) was performed, which revealed homozygous gene mutation in STX3. Using WES in clinical environment can be a useful tool for diagnosing difficult and rare inherited congenital enteropathies.
\end{abstract}

(C) 2017 The Author(s)

Published by S. Karger AG, Basel

\section{Introduction}

Microvillus inclusion disease (MVID) is a rare autosomal recessive disease that presents with severe and intractable secretory diarrhea in neonates and infants $[1,2]$. The typical MVID is a severe and intractable enteropathy requiring total parenteral nutrition (TPN) for

KARGER 
the delivery of fluids and calories, and it is inevitably fatal without continuous intravenous nutrition or intestinal transplantation [3]. However, milder variants of MVID that present later have been reported [4].

Children with the typical MVID will rapidly develop metabolic acidosis and signs of hypotonic dehydration because of profuse diarrheal losses. Physical examination shows massive abdominal distension with fluid-filled bowel loops. All children with MVID require TPN, and they are at risk of developing cholestasis and liver failure secondary to TPN [5].

Gastrointestinal endoscopy is usually normal, however, standard intestinal histology shows a variable degree of villous atrophy without marked crypt hyperplasia [6]. The accumulation of periodic acid-Schiff-positive granules within the apical cytoplasm of the immature enterocytes in the upper crypts is highly characteristic of MVID [7]. Immune staining techniques for small intestinal biopsy, directed against CD10, a neutral membraneassociated peptidase, can further help in the diagnosis of MVID [8].

In 2008, mutations in MYO5B were identified as causal for MVID. These mutations result in mislocalization of apical proteins and disrupted enterocyte polarization [9]. Recently, Wiegerinck et al. described 2 children with a MVID variant caused by a new homozygous mutation in the syntaxin 3 (STX3) gene. This new mutation was detected by WES, and it leads to loss of function of STX3. STX3 is an apical receptor involved in membrane fusion of apical vesicles in enterocytes. These 2 children presented with watery diarrhea and severe metabolic acidosis. Interestingly, tolerance towards enteral feeds was noted, however, still requiring partial parenteral nutrition (PN) and sodium bicarbonate supplements. Enterocytes in the classic and MVID variant display characteristic microvillus inclusions, which might arise from the fusion of apical transport or recycling vesicles under conditions of reduced delivery to the apical plasma membrane [10].

We are reporting the case of an infant with a MVID variant, caused by STX3 homozygous gene mutation detected by WES. To the best of our knowledge, this is the third reported case in the literature.

This report suggests that WES is a robust method for diagnosing difficult cases of congenital gastrointestinal disorders.

\section{Case Report}

A 19-day-old male Saudi infant was born at term by normal vaginal delivery to a nonconsanguineous couple, following an uneventful pregnancy. Birth weight was appropriate for gestational age. The infant was transferred to our institute for further workup because of severe vomiting, mild diarrhea, loss of weight, and metabolic acidosis, which had started at the age of 3 days. Upon admission, he was found to be dehydrated, with stunted growth, and unremarkable systemic examination apart from mild abdominal distension. Family history was remarkable for early neonatal death due to undiagnosed metabolic acidosis in a sibling and cousins.

The infant required admission to the pediatric intensive care unit (PICU) because of hypotension, hypoglycemia, and metabolic acidosis.

A full septic workup was done, and empirical intravenous antibiotic therapy was given. Extensive workup excluded infectious, metabolic, mitochondrial, immune deficiency, endocrine, and renal disorders. Abdominal ultrasound study was unremarkable. Histology of the small intestinal biopsy showed subtotal villous atrophy (Fig 1a), and the EM study was consistent with MVID (Fig. 1b). 
After exclusion of MYO5B gene mutation, WES was performed, detecting a homozygous nonsense gene mutation in STX3 (g59562908 c>T;NM_0041774:c.739C>T (p.(Arg247*).

The infant required PN therapy through a central line. Later, a gastrostomy tube was inserted and elemental milk formula was given. Enteral feed was tolerated, however, the PN therapy still contributing to most of the required calories. Growth failure and mild developmental delay are noted on follow-up, however, vomiting and diarrhea are improving with time.

\section{Discussion}

MVID (OMIM 251850) is characterized by intractable secretory diarrhea that usually begins shortly after birth [11]. It was first reported by Davidson et al. in 1978 [12] and was named "microvillus inclusion disease" by Cutz et al. [3]. A late onset variant, at 3-4 months of age, has been reported and found to have a better prognosis $[2,11]$. MVID has been described worldwide in different ethnic groups [13]. A study showed that almost half of 24 patients with MVID were from consanguineous families [14]. To date, no prevalence data for MVID are available all over the world [5]. MVID is possibly underreported in Saudi Arabia, in spite of a high prevalence of high consanguinity among Saudis [15].

The diagnosis of classic MVID is based on typical morphological abnormalities of small bowel biopsies found through a combination of light microscopy and EM in addition to the mutations in the MYO5B gene. Light microscopy detects a variable degree of villous atrophy without marked crypt hyperplasia and abnormal periodic acid-Schiff-positive secretory granules accumulating in the apical cytoplasm of mature enterocytes. EM shows an altered enterocyte brush border membrane, an increased number of secretory granules within enterocytes, and membrane-bound inclusions $[6,8,16,17]$.

Recently, a report from the Netherlands has described a mild variant of MVID in 2 children who presented with watery diarrhea and metabolic acidosis. Interestingly, they showed better tolerance to feeds, which is not the case in those affected by the classical MVID. This MVID-like phenotype is caused by homozygous new mutations in STX3. These mutations lead to loss of function of STX3, an apical receptor involved in membrane fusion of apical vesicles in enterocytes [10].

Our patient presented with severe vomiting, feeding disorder, and mild diarrhea. The frequency of the diarrhea decreased following the early introduction of enteral elemental formula. The duodenal biopsy showed marked villous atrophy, and EM study was consistent with MVID, however, there was no mutation in the MYO5B gene. Because of its high efficiency, we did WES which identified a homozygous nonsense gene mutation in STX3 (c.739C>T (p.(Arg247*). It was the same mutation which has been reported by Wiegerinck et al. [10]. To our knowledge, this is the third reported case of STX3 gene mutation in the literature causing MVID-like phenotype.

Our patient presented with mild diarrhea, but vomiting was severe. His nutritional support was mainly provided by PN, though he is tolerating some enteral feeds. This presentation is different from what has been reported by Wiegerinck et al. [10].The cases in their report presented with watery diarrhea and severe metabolic acidosis, and enteral feeds provided most of their required calories.

Light microscopy and EM of intestinal biopsy samples from the "atypical" MVID patients showed the same findings as in the classic MVID patients, with the exception of the location of the microvilli, which were seen at the basolateral membrane in the MVID variant. WES 
revealed mutations in STX3, rather than MYO5B, as the underlying cause of "atypical" MVID in these cases [10].

Life-long TPN is usually required to maintain nutrition, fluid, and electrolyte losses. No curative therapy is available till now, however, small bowel transplantation (intestinal Tx) can cure the severe diarrhea. Both TPN and intestinal Tx are associated with side effects, such as cholestasis or infections caused by the immunosuppressive drugs used after intestinal Tx. The limited therapeutic options and the severity of the disease often lead to the patients' death in early childhood $[4,5,18]$.However, the development of genome-editing techniques, such as clustered regularly interspaced short palindromic repeats (CRISPR/Cas9), has made genetic engineering of stem cells possible and provides new opportunities to perform autologous stem cell transplantation. This new technology may provide alternative treatment in the near future for patients with severe monogenic enteropathies such as MVID [19].

Our patient is currently PN dependent, with growth failure, and mild developmental delay, the latter could be explained by recurrent hypovolemia during his early life with temporary brain ischemia.

In conclusion, we have added another case of MVID variant, caused by mutation in STX3, to the scarce existing literature.

To the best of our knowledge, this is the third case reported in the literature.

WES might be the preferred strategy for analysis of difficult cases of congenital digestive disorders.

\section{Disclosure Statement}

The authors declare no conflicts of interest.

\section{References}

1 Goulet 0, Ruemmele F, Lacaille F, et al: Irreversible intestinal failure. J Pediatr Gastroenterol Nutr 2004;38:250-269.

-2 Sherman PM, Mitchell DJ, Cutz E: Neonatal enteropathies: defining the causes of protracted diarrhea of infancy. J Pediatr Gastroenterol Nutr 2004;38:16-26.

- 3 Cutz E, Rhoads JM, Drumm B, et al: Microvillus inclusion disease: an inherited defect of brush-border assembly and differentiation. N Engl J Med 1989;320:646-651.

4 Phillips AD, Schmitz J: Familial microvillous atrophy: a clinicopathological survey of 23 cases. J Pediatr Gastroenterol Nutr 1992;14:380-396.

5 Ruemmele FM, Schmitz J, Goulet O: Microvillous inclusion disease (microvillous atrophy). Orphanet J Rare Dis 2006;1:22.

6 Groisman GM, Sabo E, Meir A, Polak-Charcon S: Enterocyte apoptosis and proliferation are increased in microvillous inclusion disease (familial microvillous atrophy). Hum Pathol 2000;31:1404-1410.

7 Phillips AD, Szfranski M, Man L-Y, Wall W: Periodic acid Schiff staining abnormality in microvillous atrophy: photometric and ultrastructural studies. J Pediatr Gastroenterol Nutr 2000;30:34-42.

8 Groisman GM, Amar M, Livne E: CD10: a valuable tool for the light microscopic diagnosis of microvillous inclusion disease (familial microvillous atrophy). Am J Surg Pathol 2002,26:902-907.

-9 Müller T, Hess MW, Schiefermeier N, et al: MYO5B mutations cause microvillus inclusion disease and disrupt epithelial cell polarity. Nat Genet 2008;40:1163-1165.

10 Wiegerinck CL, et al: Loss of syntaxin 3 causes variant microvillus inclusion disease. Gastroenterology 2014;147:65-68.

11 Canani BR, Cirillo P, Terrin G: Chronic and intractable diarrhea; in Guandalini S (ed): Essential Pediatric Gastroenterology, Hepatology, and Nutrition. Chicago, McGraw-Hill, 2005, pp 25-47.

12 Davidson GP, Cutz E, Hamilton JR, Gall DG: Familial enteropathy: a syndrome of protracted diarrhea from birth, failure to thrive, and hypoplastic villus atrophy. Gastroenterology 1978;75:783-790. 


\section{Case Reports in \\ Gastroenterology}

\begin{tabular}{l|l}
\hline Case Rep Gastroenterol 2017;11:655-659 \\
\hline DOI: 10.1159/000479624 & $\begin{array}{l}\text { @ 2017 The Author(s). Published by S. Karger AG, Basel } \\
\text { www.karger.com/crg }\end{array}$ \\
\hline
\end{tabular}

Alsaleem et al.: Microvillus Inclusion Disease Variant in an Infant with Intractable Diarrhea

13 Kaneko K, Shimizu T, Fujiwara S, et al: Microvillous inclusion disease in Japan. J Pediatr 1999;135:400.

14 Halac U, Lacaille F, Joly F, et al: Microvillous inclusion disease: how to improve the prognosis of a severe congenital enterocyte disorder. J Pediatr Gastroenterol Nutr 2011;52:460-465.

15 Elmouzan MI, Al Salloum AA, Al Herbish AS, Qurachi MM, Al Omar AA: Consanguinity and major genetic disorder in Saudi children: a community-based cross-sectional study. Am Saudi Med 2008:28:169-173.

16 Bell SW, Kerner JA Jr, Sibley RK: Microvillous inclusion disease. The importance of electron microscopy for diagnosis. Am J Surg Pathol 1991;15:1157-1164.

17 Groisman GM, Ben-Izhak 0, Schwersenz A, Berant M, Fyfe B: The value of polyclonal carcinoembryonic antigen immunostaining in the diagnosis of microvillous inclusion disease. Hum Pathol 1993;24:12321237.

18 Ruemmele FM, Jan D, Lacaille F, et al: New perspectives for children with microvillous inclusion disease: early small bowel transplantation. Transplantation 2004;77:1024-1028.

19 Hong SN, Dunn JC, Stelzner M, Martín MG. Concise review: the potential use of intestinal stem cells to treat patients with intestinal failure. Stem Cells Transl Med 2016;5:1-11.
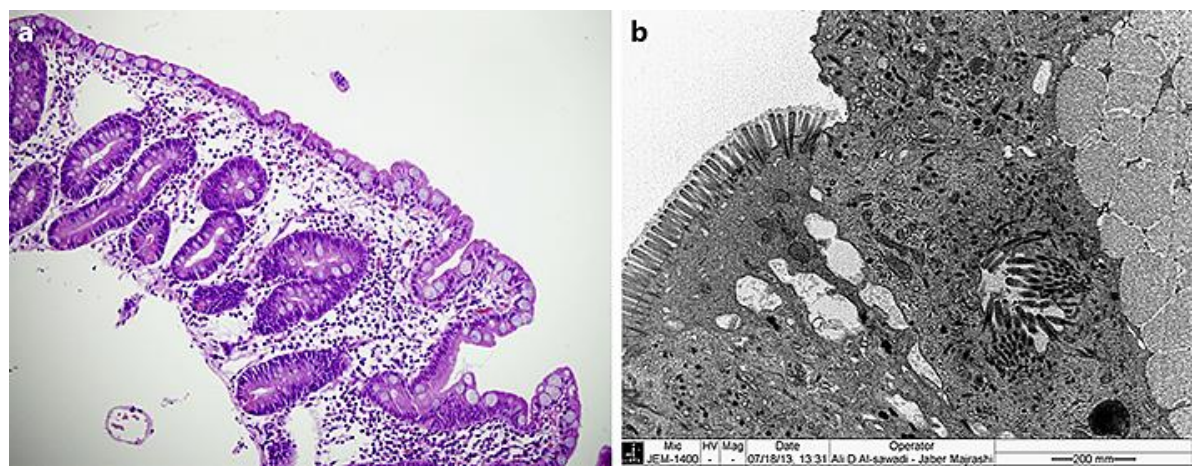

Fig. 1. Histology of duodenal biopsy specimens: a Hematoxylin and eosin stain $(H \& E, \times 40)$, near total villous atrophy with no significant intraepithelial lymphocytosis, inflammation, or crypt hyperplasia. b Transmission electron microscopy $(\times 25,000)$ shows microvillus inclusions and large membrane-bound microvillus inclusions in the apical cytoplasm of the enterocyte. The enterocytes of the duodenum show denudation and loss of the microvilli on their luminal surface with uneven gapping and spacing as well. 